\title{
Determinants of cardiorespiratory fitness in very long-term survivors of allogeneic hematopoietic stem cell transplantation: a national cohort study
}

\author{
Ole Henrik Myrdal ${ }^{1,2}$ (1) Phoi Phoi Diep ${ }^{2,3,4} \cdot$ Ellen Ruud $^{2,3} \cdot$ Lorentz Brinch $^{5} \cdot$ Richard John Massey $^{2,6} \cdot$ \\ Elisabeth Edvardsen $^{7,8} \cdot$ Johny Kongerud ${ }^{1,2} \cdot$ May B. Lund $^{1,2} \cdot$ Liv Ingunn Sikkeland $^{1,2}$
}

Received: 12 May 2020 / Accepted: 20 July 2020 / Published online: 21 August 2020

(C) The Author(s) 2020

\begin{abstract}
Purpose Survivors of allogeneic hematopoietic stem cell transplantation (allo-HSCT) are at risk for cardiopulmonary adverse events. Data on long-term effects on cardiorespiratory fitness are limited. To address the gap in knowledge, we aimed to determine peak oxygen uptake ( $\left(\mathrm{VO}_{2}\right.$ peak) and identify associations between cardiorespiratory fitness and clinical characteristics, self-reported physical activity, cardiac, and pulmonary function.

Methods In a nationwide, single-center cross-sectional study, 90 survivors [aged median (range) 35 (17-54) years, 56\% females] were examined, 17 (6-26) years after allo-HSCT. Myeloablative conditioning comprised busulfan/cyclophosphamide or cyclophosphamide only. Methods included pulmonary function tests, echocardiography, and cardiopulmonary exercise test.

Results Chronic graft-versus-host disease (cGVHD) was found in $31 \%$ of the subjects, of whom $40 \%$ had bronchiolitis obliterans syndrome (BOS). Seventy-one percent of the survivors did not meet WHO recommendations for physical activity and $42 \%$ were overweight. Reduced gas diffusion $\left(\mathrm{DL}_{\mathrm{CO}}\right.$ ) and systolic ventricular dysfunction (LVEF) were found in $44 \%$ and $31 \%$, respectively. For the group, mean (95\% CI), $\dot{\mathrm{V} O} 2$ peak was 36.4 (34.7-38.0) $\mathrm{mL} / \mathrm{min} / \mathrm{kg}$ [89 (85-93)\% of predicted]. $\dot{\mathrm{VO}}_{2}$ peak was low at $43 \%$. Cardiopulmonary factors and deconditioning were equally common limitations for exercise. In a multiple linear regression model, low $\dot{\mathrm{VO}}_{2}$ peak was associated with low $\mathrm{DL}_{\mathrm{CO}}$, low $\mathrm{LVEF}$, BOS, overweight, and inactivity.

Conclusion Half of the survivors had reduced cardiorespiratory fitness median 17 years after allo-HSCT. Cardiopulmonary factors and deconditioning were equally common limitations to exercise. We encourage long-term cardiopulmonary monitoring of allo-HSCT survivors and targeted advice on modifiable lifestyle factors.
\end{abstract}

Keywords Allogeneic hematopoietic stem cell transplantation · Long-term follow-up · Cardiorespiratory fitness · Cardiac function $\cdot$ Pulmonary function

Notation of prior abstract presentation: Parts of the results were presented at the ERS (European Respiratory Society) Annual Congress in Madrid, September 2019.

Electronic supplementary material The online version of this article (https://doi.org/10.1007/s00520-020-05644-1) contains supplementary material, which is available to authorized users.

Ole Henrik Myrdal

omyrda@ous-hf.no

1 Department of Respiratory Medicine, Oslo University Hospital, Rikshospitalet, Box 4950 Nydalen, 0424 Oslo, Norway

2 Institute of Clinical Medicine, University of Oslo, Oslo, Norway

3 Department of Pediatric Oncology and Haematology, Oslo University Hospital, Rikshospitalet, Oslo, Norway

4 Department of Pediatric Research, Division of Pediatric and Adolescent Medicine, Oslo University Hospital, Oslo, Norway
5 Department of Haematology, Oslo University Hospital, Rikshospitalet, Oslo, Norway

6 Department of Cardiology, Oslo University Hospital, Rikshospitalet, Oslo, Norway

7 Department of Physical Performance, The Norwegian School of Sport Sciences, Oslo, Norway

8 Department of Pulmonary Medicine, Oslo University Hospital Ullevål, Oslo, Norway 


\section{Introduction}

Survivors of allogeneic hematopoietic stem cell transplantation (allo-HSCT) are at risk for both cardiac and pulmonary adverse events, caused by the myeloablative conditioning prior to allo-HSCT and the immunological response induced by the hematopoietic stem cell graft after allo-HSCT $[1,2]$. In addition, most patients with hematologic malignancies have received chemotherapy with or without radiation before they became candidates for allo-HSCT.

Late-onset non-infectious pulmonary complications (LONIPCs) occur in up to one-fifth after allo-HSCT and comprise leading causes of morbidity and mortality [3]. The most frequent LONIPC is bronchiolitis obliterans syndrome (BOS), which is linked to chronic graft-versus-host disease (cGVHD) [4]. Cardiovascular disease is another cause of morbidity and mortality in long-term allo-HSCT survivors [5]. Risk factors for cardiovascular disease have been reported to be $>4$-fold higher in allo-HSCT survivors than in the general population [6], with a clear association between multiple risk factors and subsequent development of cardiovascular disease [2].

Measurement of peak oxygen uptake $\left(\mathrm{V}_{2}\right.$ peak) through cardiopulmonary exercise test (CPET) represents the gold standard assessment of cardiorespiratory fitness and is useful to assess the global effect of cardiac and/or pulmonary impairments [7]. CPET also provides information about the risk of cardiovascular disease, all-cause mortality, and cancer mortality $[8,9]$.

Cardiorespiratory fitness in long-term survivors of allo-HSCT has been scarcely investigated [10-14]. Furthermore, most previous studies have been restricted to children $[12,14]$ or been limited by small and/or inhomogeneous patient materials [11, 13], and followup has not exceeded 10 years [10-14]. In Norway, all allo-HSCTs have been performed at Oslo University Hospital. The patients were recruited from the entire country, referred and selected according to uniform criteria, and subjected to standardized treatment procedures. Today, this single-center policy has provided us with a well-defined national patient population available for follow-up.

In the present study, our primary aim was to determine cardiorespiratory fitness assessed by $\mathrm{VO}_{2}$ peak in a nationwide cohort of young very long-term allo-HSCT survivors, who had received myeloablative conditioning with chemotherapy only and not total body irradiation (TBI). Secondly, we aimed to identify associations between cardiorespiratory fitness and clinical characteristics, self-reported level of physical activity, and cardiac and pulmonary function.

\section{Methods}

\section{Design and study population}

The study was part of a large, nationwide cross-sectional study covering a broad range of late treatment-related effects, conducted at Oslo University Hospital $[15,16]$. All subjects were survivors of allo-HSCT, performed in childhood or early adulthood. Inclusion criteria were age $<30$ years at alloHSCT, $>16$ years at the time of the survey, and minimum 5 -year follow-up. At the time of the survey, 157 subjects were alive, and 104 subjects participated (Fig. 1). Exclusion criteria in the present study were TBI conditioning $(n=6)$, cardiovascular contraindications $(n=5)$, and physical inability to perform CPET, using wheelchair $(n=3)$. Cardiovascular contraindications included severe, untreated hypertension, coronary fistula to the pulmonary artery, cardiomyopathy, aortic valve stenosis, and significant pulmonary hypertension. In total, 90 subjects aged [median (range) 35 (17-54) years, 56\% females] were included. The Regional Committee for Medical and Health Research Ethics (2014/370) approved the study. Written informed consent was obtained from all participants.

\section{Clinical assessment}

At follow-up, medical records were reviewed for treatment data. All participants underwent a medical examination, blood sampling, and a standardized interview. Age, gender, body mass index (BMI, $\mathrm{kg} / \mathrm{m}^{2}$ ), smoking habits, physiciandiagnosed cardiovascular or pulmonary disease, and current medication were registered (Table 1). Overweight was defined as BMI $\geq 25 \mathrm{~kg} / \mathrm{m}^{2}$ and obesity $\mathrm{BMI} \geq 30 \mathrm{~kg} / \mathrm{m}^{2}$, according to the World Health Organization (WHO) Classification [17]. The self-reported physical activity level was assessed using the WHO recommendations [18]. The survivors were categorized as meeting the recommendations if their activity included $\geq 150 \mathrm{~min} /$ week with moderate-intensity exercise or $\geq$ $75 \mathrm{~min} /$ week with high-intensity exercise. cGVHD was diagnosed according to the National Institute of Health (NIH) criteria [19]. Hypertension was defined as current treatment with antihypertensive agents.

\section{Blood samples}

Fasting blood samples were collected at 8:00 am and analyzed for hemoglobin, lipids, glycated hemoglobin $(\mathrm{HbAlc})$, and Nterminal proB-type natriuretic peptide (proBNP). For $\mathrm{Hb}$ and proBNP, the hospital's reference values for males and females were used $(\mathrm{Hb} 13.4-17.0 \mathrm{~g} / \mathrm{dL}$ and 11.7-15.3, and proBNP $<$ $10 \mathrm{pmol} / \mathrm{L}$ and $<20 \mathrm{pmol} / \mathrm{L}$ in the age group $18-48$ years, respectively). Hypercholesterolemia was defined as lowdensity lipoprotein $>4.1 \mathrm{mmol} / \mathrm{L}$ or the use of lipid- 
Fig. 1 Study selection of longterm survivors after allogeneic HSCT

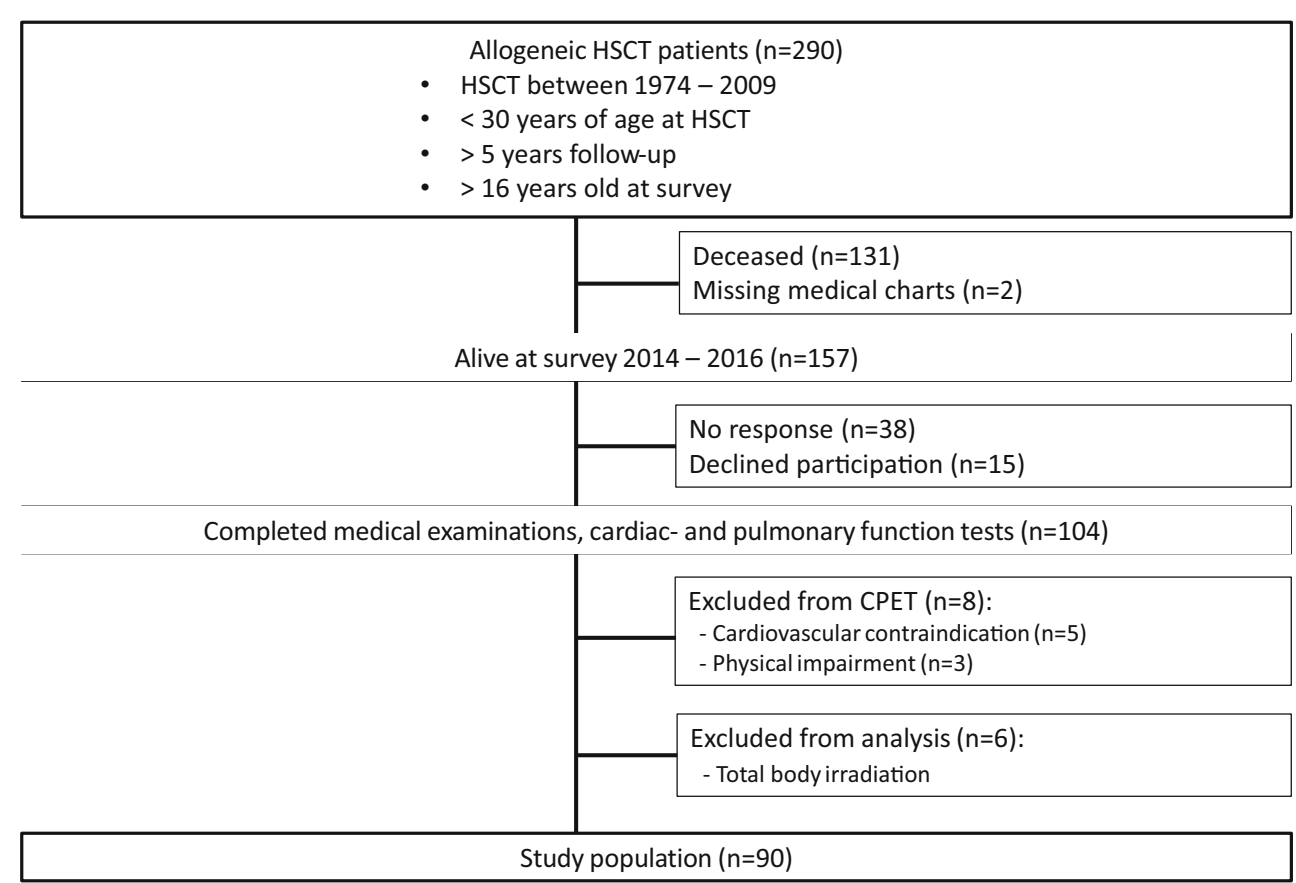

lowering agents. Diabetes mellitus was defined as HbA1c > $6.5 \%$ or the current use of antidiabetic medication.

\section{Pulmonary function}

Pulmonary function measurements (Jaeger Master Screen Body, Würzburg, Germany) were performed in accordance with the guidelines of ERS [20, 21]. Recorded variables were total lung capacity (TLC), residual volume (RV), forced vital capacity (FVC), forced expiratory volume in $1 \mathrm{~s}\left(\mathrm{FEV}_{1}\right)$, and gas diffusion capacity $\left(\mathrm{DL}_{\mathrm{CO}}\right)$. The predicted values for FVC and $\mathrm{FEV}_{1}$ were taken from the Global Lung Initiative [22] and static lung volumes and $\mathrm{DL}_{\mathrm{CO}}$ from the European Community for Steel and Coal [23]. Obstructive impairment, i.e., BOS, was diagnosed according to NIH criteria [19]. Restrictive impairment was defined as TLC $<80 \%$ of predicted value, and gas diffusing impairment as $\mathrm{DL}_{\mathrm{CO}}<80 \%$ of predicted value, corresponding to the lower 5 th percentile of the reference material and in line with ERS recommendations [24].

\section{Echocardiography}

Echocardiography was performed according to international recommendations [25], using E9 scanners from GE (Horten, Norway). All recordings were obtained by one single sonographer and reviewed by a senior cardiologist, both blinded to all clinical data. Left ventricular ejection fraction (LVEF) was assessed by calculating the modified Simson's method [25]. Left ventricular systolic dysfunction was defined as LVEF < $52 \%$ for men and $<54 \%$ for women [25].

\section{Cardiopulmonary exercise test}

All CPETs were performed with the subjects walking on a treadmill (TechnoGym Runrace, Forli, Italy) using a modified Balke protocol [26], the same protocol used for the reference population [27]. In short, after a warm-up phase at $3 \mathrm{~km} / \mathrm{h}$ and a $2 \%$ inclination, the inclination was increased by $2 \%$ every $60 \mathrm{~s}$ up to $20 \%$. Then, the speed was increased by $0.5 \mathrm{~km} / \mathrm{h}$ every $60 \mathrm{~s}$ until exhaustion. During the test, metabolic gas exchange and ventilatory variables were measured continuously breath-by-breath and averaged over 30-s intervals (Vyntus CPX, CareFusion, Hoechberg, Germany) through a two-way breathing mask (2700 series, Hans Rudolph, inc. Shawnee, USA). Calibration of flow and gas concentration was performed before each test. Maximal heart rate $\left(\mathrm{HR}_{\max }\right)$ was recorded with a 12-lead ECG (CustoMed, Ottobrunn, Germany). The test was discontinued at exhaustion, reporting Borg scale 18-20 [28], and respiratory exchange ratio (RER) $>1.10 . \mathrm{VO}_{2}$ peak predicted was calculated from the equations of Edvardsen et al. [27]. Low cardiorespiratory fitness was defined as $\dot{\mathrm{VO}}_{2}$ peak $<85 \%$ of predicted, in accordance with ATS/ACCP guidelines [29]. The ventilatory limitation was defined as breathing reserve $\leq 15 \%$ or $11 \mathrm{~L} / \mathrm{min}$ [30], and gas exchange limitation was defined as $\mathrm{V}_{\mathrm{E}} /$ $\dot{\mathrm{V}}_{\mathrm{CO} 2}$ slope $\geq 34$ [31]. The cardiac limitation was defined as oxygen pulse $<80 \%$ of predicted, HR $<90 \%$ of agepredicted, and HR reserve $<15$ beats/min in absences of pulmonary limitations [29]. Oxygen pulse was calculated dividing $\mathrm{V}_{2}$ peak $\left(\mathrm{mL} \min ^{-1}\right)$ by $\mathrm{HR}_{\max }$ [29]. Deconditioning was defined as low $\dot{\mathrm{VO}}_{2}$ peak in absence of cardiac or pulmonary limitations. 
Table 1 Characteristics of 90 long-term survivors of allogeneic HSCT

\begin{tabular}{|c|c|}
\hline & $n=90$ \\
\hline Male/female, $n(\%)$ & $40 / 50(44 / 56 \%)$ \\
\hline Age at transplantation, median (range) & $20(0.3-30)$ \\
\hline Age at follow-up, median (range) & $35(17-54)$ \\
\hline Years of observation, median (range) & $17(6-26)$ \\
\hline BMI, $\mathrm{kg} / \mathrm{m}^{2}$, median (range) & $23.8(15.8-43.8)$ \\
\hline Overweight (BMI 25.0-29.9 kg/m²), $n(\%)$ & $25(28 \%)$ \\
\hline Obese $\left(\mathrm{BMI} \geq 30 \mathrm{~kg} / \mathrm{m}^{2}\right), n(\%)$ & $13(14 \%)$ \\
\hline Diabetes & $2(2 \%)$ \\
\hline Physician-diagnosed asthma pre-allo-HSCT, $n(\%)$ & $9(10 \%)$ \\
\hline \multicolumn{2}{|l|}{ Smoking } \\
\hline Never, $n(\%)$ & $61(68 \%)$ \\
\hline Former, $n(\%)$ & $16(18 \%)$ \\
\hline Daily, $n(\%)$ & $13(14 \%)$ \\
\hline Pack-years, median (range) & $3(1-24)$ \\
\hline \multicolumn{2}{|l|}{ Underlying diagnosis } \\
\hline Malignancy, $n(\%)$ & $66(73 \%)$ \\
\hline Acute myeloid leukemia, $n(\%)$ & $30(33 \%)$ \\
\hline Chronic myeloid leukemia, $n(\%)$ & $20(22 \%)$ \\
\hline Acute lymphoblastic leukemia, $n(\%)$ & $9(10 \%)$ \\
\hline Other malignant, $n(\%)$ & $7(8 \%)$ \\
\hline Severe aplastic anemia, $n(\%)$ & $15(17 \%)$ \\
\hline Other non-malignant, $n(\%)$ & $9(10 \%)$ \\
\hline \multicolumn{2}{|l|}{ Conditioning } \\
\hline $\begin{array}{l}\text { Cyclophosphamide/busulfan or } \\
\text { cyclophosphamide, } n(\%)\end{array}$ & $88(98 \%)$ \\
\hline None, $n(\%)$ & $2(2 \%)$ \\
\hline \multicolumn{2}{|l|}{ Donor } \\
\hline Matched related donor, $n(\%)$ & $56(62 \%)$ \\
\hline Matched unrelated donor, $n(\%)$ & $27(30 \%)$ \\
\hline Haploidentical donor, $n(\%)$ & $7(8 \%)$ \\
\hline \multicolumn{2}{|l|}{ Graft-vs-host disease } \\
\hline \multicolumn{2}{|l|}{ Diagnosed earlier } \\
\hline Acute, grades $0-\mathrm{I}, n(\%)$ & $66(73 \%)$ \\
\hline Acute, grades II-IV, $n(\%)$ & $24(27 \%)$ \\
\hline Chronic, limited, and extensive, $n(\%)$ & $35(39 \%)$ \\
\hline \multicolumn{2}{|l|}{ Diagnosed at follow-up } \\
\hline Chronic, grades 1-3 (NIH criteria), $n(\%)$ & $28(31 \%)$ \\
\hline Bronchiolitis obliterans syndrome, $n(\%)$ & $11(11 \%)$ \\
\hline
\end{tabular}

Allo-HSCT, allogeneic hematopoietic stem cell transplantation; $B M I$, body mass index

\section{Reference population}

The reference population has been described previously [27]. In brief, in a multicenter study involving regional centers throughout Norway, 759 healthy adults successfully completed CPET on a treadmill. In total, 558 subjects ( $48 \%$ females) were within the same age range as the participants in the present study.

\section{Statistical analysis}

Student $t$ test or Mann-Whitney $U$ test was used, as appropriate, to compare continuous data between groups, and the chisquare test or Fisher's exact test to compare categorical variables. Univariate and multiple linear regression analyses were used to detect associations between outcome variables and determinants of interest. The independent variables entered the regression models were those hypothesized a priori for biological or clinical reasons or found to be significant at a $20 \%$ level by univariate analysis. Due to collinearity, only one variable from the pulmonary function tests and one agerelated variable were included in the final model. Pulmonary function in patients with BOS was analyzed separately since the diagnostic criteria for BOS are based on such tests [19]. Since the chemotherapy regimen used in the treatment of malignant blood disorders may affect both cardiac and pulmonary function, we chose to analyze the relevant variables according to chemotherapy prior to allo-HSCT (yes vs no). A two-sided $p$ value $\leq 0.05$ was considered significant. Standard statistical analyses were performed with SPSS (IBM SPSS, v26).

\section{Results}

Clinical characteristics are outlined in Table 1. In total, $42 \%$ of the subjects were overweight, $14 \%$ obese. Subjects with overweight were more frequently treated for hypertension ( $42 \%$ vs $21 \%, p=0.03)$ and hypercholesterolemia (29\% vs $8 \%, p=$ 0.008 ) than those with normal weight. Hematological malignancies comprised the underlying diagnosis in $66(73 \%)$ of the patients of whom 41 (46\%) had received treatment with chemotherapy regimens prior to allo-HSCT. Patients diagnosed with chronic myeloid leukemia did not receive chemotherapy routinely, in contrast to the other malignant disorders. Myeloablative conditioning with busulfan/ cyclophosphamide or cyclophosphamide had been applied in $98 \%$ of the subjects. Two patients with severe combined immunodeficiency did not receive a conditioning regimen. cGVHD (grades 1-3) was diagnosed in 28 (31\%) of the survivors and was associated with chemotherapy prior to alloHSCT $(p=0.005)$. Eleven of the 28 patients with cGVHD had developed BOS. The genders were comparable with respect to all clinical characteristics. The non-responders were younger than those who participated in the study [(median, range) 25 (18-53) vs $35(17-54)$ years, $p<0.001]$ and comprised more males ( $70 \%$ vs $44 \%, p=0.01$ ) but were comparable with respect to malignant vs non-malignant disease prior to allo-HSCT. Pulmonary and cardiac functions according to chemotherapy prior to allo-HSCT are summarized in Table 2 . For the entire study group, mean lung volumes and $\mathrm{DL}_{\mathrm{CO}}$ were above $80 \%$ predicted; however, $44 \%$ had impaired 
Table 2 Blood test, pulmonary, and cardiac function of 90 long-term survivors of allo-HSCT according to chemotherapy prior to HSCT (no/yes)

\begin{tabular}{|c|c|c|c|c|c|}
\hline & All & No & Yes & $p$ value & BOS* \\
\hline Pulmonary function & $n=90$ & $n=46(51 \%)$ & $n=33(37 \%)$ & & $n=11(12 \%)$ \\
\hline TLC \% predicted & $104(101-106)$ & $105(101-108)$ & $103(98-107)$ & 0.71 & $105(98-112)$ \\
\hline RV \% predicted & $117(112-123)$ & $115(108-122)$ & $120(111-129)$ & 0.89 & $157(145-170)$ \\
\hline FVC $\%$ predicted & $93(90-96)$ & $96(92-100)$ & $90(86-95)$ & 0.36 & $80(73-87)$ \\
\hline $\mathrm{FEV}_{1} \%$ predicted & $88(84-92)$ & $92(87-97)$ & $84(78-90)$ & 0.17 & $56(46-66)$ \\
\hline $\mathrm{FEV}_{1} / \mathrm{FVC}$ & $0.78(0.75-0.80)$ & $0.79(0.76-0.83)$ & $0.76(0.73-0.79)$ & 0.19 & $0.58(0.50-0.66)$ \\
\hline $\mathrm{DL}_{\mathrm{CO}} \%$ predicted & $83(80-87)$ & $87(83-92)$ & $79(75-84)$ & 0.02 & $85(74-95)$ \\
\hline Cardiac function & & $n=49(54 \%)$ & $n=41(46 \%)$ & & \\
\hline $\operatorname{LVEF}(\%)$ & $55(54-56)$ & $57(55-58)$ & $54(51-56)$ & 0.01 & \\
\hline Left ventricular dysfunction & $28(31 \%)$ & $6(25 \%)$ & $22(33 \%)$ & 0.02 & \\
\hline Hypercholesterolemia & $15(17 \%)$ & $1(5 \%)$ & $14(25 \%)$ & 0.51 & \\
\hline Hypertension & $37(41 \%)$ & $6(27 \%)$ & $31(54 \%)$ & 0.18 & \\
\hline \multicolumn{6}{|l|}{ Blood analysis } \\
\hline proBNP, $\mathrm{pmol} / \mathrm{L}^{\dagger}$ & $5.5(0.7-79.0)$ & $3.9(0.7-19.0)$ & $9.0(1.4-79.0)$ & $<0.001$ & \\
\hline $\mathrm{CRP}, \mathrm{mg} / \mathrm{L}^{\dagger}$ & $1.5(0.6-14.0)$ & $1.2(0.6-14.0)$ & $1.7(0.6-12.0)$ & 0.11 & \\
\hline $\mathrm{Hb}, \mathrm{g} / \mathrm{dl}$ & $14.3(14.1-14.6)$ & $14.3(14-14.7)$ & $14.3(13.8-14.7)$ & 0.78 & \\
\hline $\mathrm{HbA} 1 \mathrm{c}^{\dagger}$ & $5.4(4.2-6.7)$ & $5.3(5.2-5.4)$ & $5.4(5.3-5.6)$ & 0.13 & \\
\hline
\end{tabular}

*BOS patients were separated in a column for the pulmonary function values. $H S C T$, hematopoietic stem cell transplantation; BOS, bronchiolitis obliterans syndrome; $T L C$, total lung capacity; $R V$, residual volume; $F V C$, forced vital capacity; $F E V_{l}$, forced expiratory volume-one second; $D L_{C O}$, diffusing capacity for carbon monoxide; $L V E F$, left ventricular ejection fraction; $p r o B N P$, pro B-type natriuretic peptide; $C R P$, C-reactive protein; $H b$, hemoglobin concentration; $H b A l c$, glycated hemoglobin. Data are presented as mean (95\% confidence interval), number (\%) or $\dagger$ median (range)

$\mathrm{DL}_{\mathrm{CO}}$. Patients who had received chemotherapy prior to alloHSCT had lower $\mathrm{DL}_{\mathrm{CO}} \%$ predicted than those who had not received such treatment [mean $(95 \% \mathrm{CI}) 79(75-84)$ vs 87 (83-92), $p=0.02]$. Patients with BOS had increased RV and reduced $\mathrm{FEV}_{1}, \mathrm{FVC}$, and $\mathrm{FEV}_{1} / \mathrm{FVC}$, thus confirming that they met the NIH criteria.

As a group, the survivors had mean LVEF above the lower limit. However, left ventricular systolic dysfunction was found in $31 \%$ of the subjects and was associated with having received chemotherapy prior to allo-HSCT $(p=0.02)$. The subjects with left ventricular systolic dysfunction also had higher levels of proBNP than those with normal LVEF [median (range) $7.9(0.8-79.0)$ vs $4.7(0.7-35.0) \mathrm{pmol} / \mathrm{L}, p=$ 0.03]. There was no significant difference in LVEF between patients with and without cGVHD.

The main results from CPET are presented in Fig. 2. For the entire study group, $\mathrm{VO}_{2}$ peak was mean $(95 \% \mathrm{CI}) 36.4$ (34.7-38.0) $\mathrm{mL} \mathrm{kg}^{-1} \mathrm{~min}^{-1}$, corresponding to $89(85-93) \%$ of the predicted value. Low cardiorespiratory fitness was found in $39(43 \%)$ of the subjects. Survivors with BMI $\geq 25$ had lower $\dot{\mathrm{VO}}_{2}$ peak \% predicted than those with normal weight [84\% (79-89) vs 92\% (87-98), $p=0.03$ ]. Only $29 \%$ of the survivors met the WHO recommendations for physical activity. Those who met the recommendations had higher mean $\mathrm{VO}_{2}$ peak \% predicted than those who did not [95 (86$104)$ vs $86(82-90), p=0.04]$. Survivors with BOS had reduced $\dot{\mathrm{VO}}_{2}$ peak \% predicted compared with those without BOS [76 (66-86) vs 91 (87-95), $p=0.01]$. Those with BOS also had reduced breathing reserve $(p=0.002)$ and HR reserve $(p=0.01)$. There was a positive correlation between $\dot{\mathrm{VO}}_{2}$ peak $\%$ predicted and, respectively, $\mathrm{LVEF}$ and $\mathrm{DL}_{\mathrm{CO}} \%$ predicted $(p=0.04$ and 0.06$)$.

Detailed data on cardiorespiratory responses during CPET are presented in Supplement 1. All subjects were able to obtain peak effort (Borg scale $\geq 18$ and/or RER $\geq 1.10$ ). Of the $39(43 \%)$ subjects with low cardiorespiratory fitness, 22 (56\%) were deconditioned, while $17(44 \%)$ had either cardiac ( $n=6)$, lung volume $(n=6)$, gas exchange $(n=2)$, or several limiting factors $(n=3)$. In a multiple linear regression model, low $\dot{\mathrm{VO}}_{2}$ peak \% predicted was significantly associated with high BMI, not meeting WHO recommendations for physical activity, BOS, low $\mathrm{DL}_{\mathrm{CO}} \%$ predicted, and reduced LVEF (Table 3).

\section{Discussion}

The study demonstrated that median 17 years after alloHSCT, only half of the survivors had normal cardiorespiratory fitness assessed by $\dot{\mathrm{VO}}_{2}$ peak. Among the survivors with low cardiorespiratory fitness, both cardiopulmonary factors and deconditioning were found to limit exercise and were equally 
Fig. 2 The main results from CPET showing VंO2peak \% predicted (mean $95 \% \mathrm{CI}$ ) and key variables

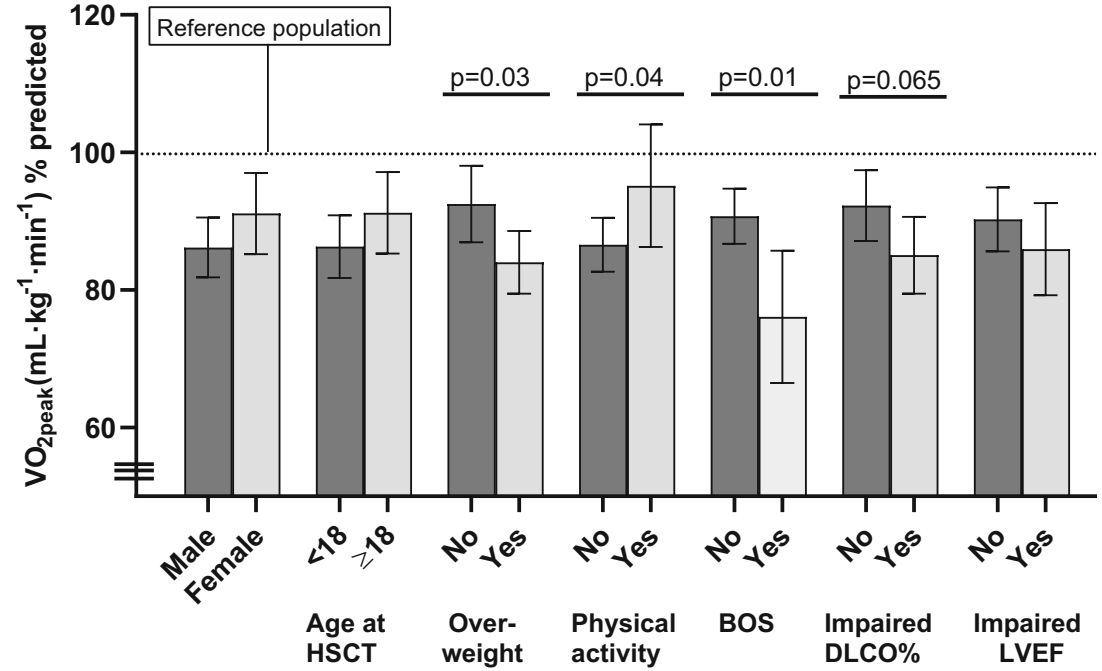

common. Low cardiorespiratory fitness was associated with reduced gas diffusion capacity, reduced systolic ventricular function, BOS, and overweight and inactivity. In sum, these findings encourage long-term monitoring of survivors after allo-HSCT and highlight the need for increased focus on modifiable lifestyle factors in oncology survivorship clinics.

Several previous studies have reported reduced cardiorespiratory fitness after allo-HSCT [10-14]. However, nearly all those studies were performed in children and adolescents [11-14]. Eames et al. estimated that as much as $68 \%$ of their cohort had $\dot{\mathrm{VO}}_{2}$ peak < 80\% predicted [12]. Larsen et al. [11] and Hogarty et al. [13] found impaired cardiorespiratory fitness with reduced $\dot{\mathrm{VO}}_{2}$ peak in $55 \%$ and $69 \%$ of the patients, respectively. Those studies all had small sample sizes $(<40)$, comprised heterogeneous groups including patients with both blood disorders and lymphomas, TBI conditioning, and mean follow-up was < 7 years. One larger study including young patients (mean age 14 years) with blood disorders only reported reduced $\dot{\mathrm{VO}}_{2}$ peak in $25 \%$ of 63 survivors with mean observation 7 years [14]. To our knowledge, only one previous long-term study has been performed in adults [10]. That study was confined to an older population (median age 67 years), but included only 20 subjects (10 allo-HSCT and 10 auto-HSCT), and found, on average, 22\% lower $\dot{\mathrm{VO}}_{2}$ peak in the survivors as compared with predicted. None of the studies above is directly comparable to ours since we studied very long-term effects of allo-HSCT in young adults conditioned with chemotherapy only.

We found that mean $\dot{\mathrm{VO}}_{2}$ peak was $89 \%$ of predicted, adjusted for gender and age. This is considerably higher than in the studies above. Furthermore, none of our survivors had $\dot{\mathrm{VO}}_{2}$ peak $<16 \mathrm{~mL} \mathrm{~kg}^{-1} \mathrm{~min}^{-1}$, a threshold reported to be associated with a 9-fold risk of death in allo-HSCT patients [32]. Given the other studies, all had much shorter observation periods than ours, there is a possibility that $\dot{\mathrm{VO}}_{2}$ peak may improve over time. Survivorship bias is another potential explanation, suggesting that very long-term allo-HSCT survivors eligible for CPET comprise a selected group who has been spared serious complications. Another factor is the mode of exercise testing. The survivors in our study were tested on a treadmill while in the other studies - except one [12] - the

Table 3 Univariate and multiple regression analysis using $\mathrm{VO}_{2}$ peak $\%$ of predicted as dependent variable in long-term survivors of allo-HSCT $(n=90)$

\begin{tabular}{|c|c|c|c|c|c|c|}
\hline Variable & Unadjusted ( $(\beta)$ & $95 \% \mathrm{CI}$ & $p$ value & Adjusted $(ß)^{1}$ & $95 \% \mathrm{CI}$ & $p$ value \\
\hline Female gender & 5 & $(-2.6,12.6)$ & 0.2 & & & \\
\hline BMI & -1.1 & $(-1.8,-0.4)$ & 0.002 & -1.4 & $(-2.0,-0.8)$ & $<0.001$ \\
\hline Age at allo-HSCT & 0.2 & $(-0.2,0.6)$ & 0.26 & & & \\
\hline Chronic GVHD w/o BOS & -2.5 & $(-10.8,5.8)$ & 0.55 & & & \\
\hline BOS & -14.6 & $(-25.8,-3.4)$ & 0.01 & -15.2 & $(-24.9,-5.4)$ & 0.003 \\
\hline Physical activity & 8.8 & $(0.6,17.0)$ & 0.04 & 7.3 & $(0.2,14.4)$ & 0.04 \\
\hline $\mathrm{DL}_{\mathrm{CO}} \%$ of predicted & 0.2 & $(-0.01,0.5)$ & 0.06 & 0.2 & $(0.04,0.5)$ & 0.02 \\
\hline LVEF & 0.6 & $(-0.03,1.3)$ & 0.06 & 0.6 & $(0.07,1.2)$ & 0.03 \\
\hline
\end{tabular}

${ }^{1}$ Adjusted for all shown variables. Allo-HSCT, Allogeneic hematopoietic stem cell transplantation; BOS, bronchiolitis obliterans syndrome; BMI, body mass index; $G V H D$, graft-versus-host disease; $D L_{C O}$, diffusing capacity for carbon monoxide; physical activity according to the World Health Organization recommendation; $L V E F$, left ventricular ejection fraction 
subjects were tested on a cycle ergometer. Walking on a treadmill is a more functional way of moving than cycling; it places a higher demand on the cardiorespiratory system and is known to elicit 10-20\% higher $\mathrm{V}_{2}$ peak because larger muscle groups are involved [29]. Finally, in contrast to the other mentioned studies, the survivors in our study had not been treated with TBI that may cause both cardiac and pulmonary injury [33].

About half of the survivors with low cardiorespiratory fitness were deconditioned. Deconditioning is closely linked to modifiable lifestyle factors such as overweight and inactivity. More than $70 \%$ of the survivors did not meet the WHO recommendations for physical activity, and $42 \%$ were overweight. Those with overweight had features of metabolic syndrome (hypertension, dyslipidemia). A report from the St. Jude Lifetime Cohort Study concluded that long-term adult survivors of childhood and adolescent malignancies were more likely to have metabolic syndrome with $>2$-fold relative risk if they did not follow physical activity and diet guidelines set out by the World Cancer Research Fund and American Institute for Cancer [34]. The metabolic syndrome is associated with cardiovascular death and increased mortality by all causes, and even low levels of physical activity may reduce the risk [35].

Cardiovascular disease has been shown to be a leading cause of late morbidity and mortality after allo-HSCT [2] and survivors of allo-HSCT have a 4-fold higher risk of developing cardiovascular disease when compared with the general population [6]. A report from the Blood and Marrow Transplant Survivor Study-2 provided data on cause-specific late mortality after allo-HSCT [36]. In a large cohort ( $n=$ 764 ), the most common causes of death among those surviving $>10$ years were secondary malignancies (36\%), infection (22\%), and cardiac disease (14\%).

Late adverse effects of allo-HSCT on cardiac function have been reported in several studies $[5,6,37,38]$. In a recent study, Vandekerckhove et al. found echocardiographic signs of systolic and diastolic dysfunction as well as reduced cardiorespiratory fitness in a cohort of 43 children (mean age 13.6 years, mean 6.6 years after allo-HSCT) compared with healthy controls [39]. In our study, none of the survivors had signs or symptoms of manifest left ventricular dysfunction at rest, and for the total study group, mean LVEF was normal. One-third of the subjects had systolic dysfunction, but only two subjects had LVEF $<40 \%$. We found that LVEF was significantly associated with $\mathrm{V}_{2}$ peak \% predicted, suggesting that subclinical left ventricular dysfunction may have contributed to low cardiorespiratory fitness.

\section{Strengths and limitations}

The main strengths of the present study are a homogeneous national cohort, very long-term follow-up, and comprehensive cardiopulmonary evaluation with methods that permit detecting key organ-specific impairments. A weakness is the lack of pretreatment data, which prevents the analysis of longitudinal changes. Since age at diagnosis ranged from 0.3 to 30 years, it might have been possible to obtain reliable baseline CPET results from a subset of the patients. The survivors are young adults and longitudinal data are needed to determine if their cardiorespiratory fitness will improve, deteriorate, or remain stable throughout their adulthood. Furthermore, the crosssectional design does not permit us to define causal relationships. Although we consider an attendance rate of $66 \%$ to be acceptable in a very long-term follow-up study, we cannot rule out that non-response bias has affected the external validity and generalizability of our results since the non-responders were somewhat younger than the participants and comprised more males. However, our non-response findings mirror those reported in a recent nationwide Norwegian study of young cancer survivors that found no evidence of non-response bias [40].

\section{Conclusions and recommendations}

Half of the survivors had reduced cardiorespiratory fitness median 17 years after allo-HSCT without TBI conditioning. Cardiopulmonary factors and deconditioning were equally common limitations to exercise. We recommend targeted advice on modifiable lifestyle factors and encourage allo-HSCT survivors to follow guidelines for physical activity and diet set out by national and international cancer federations. Life-long alertness for the prevention and detection of cardiopulmonary late effects is also recommended for this increasing population of vulnerable long-term allo-HSCT survivors.

Authors' contributions All authors contributed to the design of the study, to the interpretation of the results, and in revising the manuscript. O.H.M., R.J.M., and P.P.D. participated in data collection. O.H.M., M.B.L., and L.I.B.S. drafted the manuscript. The final version has been approved by all authors.

Funding information Open Access funding provided by University of Oslo (incl Oslo University Hospital). The study has been partially financed by the Norwegian Extra Foundation for Health and Rehabilitation project no. 2013-2-230 and the South-Eastern Norway Regional Health Authority, Norway grant no. 2015084.

Data availability The datasets generated during and/or analyzed during the current study are available from the corresponding author on reasonable request.

\section{Compliance with ethical standards}

Conflict of interest The authors declare that they have no conflict of interest.

Ethical approval The study was approved by the Regional Committee for Medical and Health Research Ethics (2014/370) and the Data Protection Officer at Oslo University Hospital. 
Consent to participate Written informed consent was obtained from all participants.

\section{Code availability Not applicable.}

Open Access This article is licensed under a Creative Commons Attribution 4.0 International License, which permits use, sharing, adaptation, distribution and reproduction in any medium or format, as long as you give appropriate credit to the original author(s) and the source, provide a link to the Creative Commons licence, and indicate if changes were made. The images or other third party material in this article are included in the article's Creative Commons licence, unless indicated otherwise in a credit line to the material. If material is not included in the article's Creative Commons licence and your intended use is not permitted by statutory regulation or exceeds the permitted use, you will need to obtain permission directly from the copyright holder. To view a copy of this licence, visit http://creativecommons.org/licenses/by/4.0/.

\section{References}

1. Inaba H, Yang J, Pan J, Stokes DC, Krasin MJ, Srinivasan A, Hartford CM, Pui CH, Leung W (2010) Pulmonary dysfunction in survivors of childhood hematologic malignancies after allogeneic hematopoietic stem cell transplantation. Cancer. 116(8):2020 2030

2. Armenian SH, Sun CL, Vase T, Ness KK, Blum E, Francisco L, Venkataraman K, Samoa R, Wong FL, Forman SJ, Bhatia S (2012) Cardiovascular risk factors in hematopoietic cell transplantation survivors: role in development of subsequent cardiovascular disease. Blood. 120(23):4505-4512

3. Bergeron A, Chevret S, Peffault de Latour R, Chagnon K, de Margerie-Mellon C, Riviere F et al (2018) Noninfectious lung complications after allogeneic haematopoietic stem cell transplantation. Eur Respir J 51(5)

4. Bergeron A (2017) Late-onset noninfectious pulmonary complications after allogeneic hematopoietic stem cell transplantation. Clin Chest Med 38(2):249-262

5. Tichelli A, Bhatia S, Socie G (2008) Cardiac and cardiovascular consequences after haematopoietic stem cell transplantation. Br J Haematol 142(1):11-26

6. Chow EJ, Wong K, Lee SJ, Cushing-Haugen KL, Flowers ME, Friedman DL et al (2014) Late cardiovascular complications after hematopoietic cell transplantation. Biol Blood Marrow Transplant 20(6):794-800

7. Jones LW, Eves ND, Haykowsky M, Joy AA, Douglas PS (2008) Cardiorespiratory exercise testing in clinical oncology research: systematic review and practice recommendations. Lancet Oncol 9(8):757-765

8. Schmid D, Leitzmann MF (2015) Cardiorespiratory fitness as predictor of cancer mortality: a systematic review and meta-analysis. Ann Oncol 26(2):272-278

9. Lakoski SG, Willis BL, Barlow CE, Leonard D, Gao A, Radford NB, Farrell SW, Douglas PS, Berry JD, DeFina LF, Jones LW (2015) Midlife cardiorespiratory fitness, incident cancer, and survival after cancer in men: the Cooper Center Longitudinal Study. JAMA Oncol 1(2):231-237

10. Armenian SH, Horak D, Scott JM, Mills G, Siyahian A, Berano Teh J, Douglas PS, Forman SJ, Bhatia S, Jones LW (2017) Cardiovascular function in long-term hematopoietic cell transplantation survivors. Biol Blood Marrow Transplant 23(4):700-705
11. Larsen RL, Barber G, Heise CT, August CS (1992) Exercise assessment of cardiac-function in children and young-adults before and after bone-marrow transplantation. Pediatrics. 89(4):722-729

12. Eames GM, Crosson J, Steinberger J, Steinbuch M, Krabill K, Bass J, Ramsay NKC, Neglia JP (1997) Cardiovascular function in children following bone marrow transplant: a cross-sectional study. Bone Marrow Transplant 19(1):61-66

13. Hogarty AN, Leahey A, Zhao H, Hogarty MD, Bunin N, Cnaan A, Paridon SM (2000) Longitudinal evaluation of cardiopulmonary performance during exercise after bone marrow transplantation in children. J Pediatr 136(3):311-317

14. Mathiesen S, Uhlving HH, Buchvald F, Hanel B, Nielsen KG, Muller K (2014) Aerobic exercise capacity at long-term follow-up after paediatric allogeneic haematopoietic SCT. Bone Marrow Transplant 49(11):1393-1399

15. Pathak M, Diep PP, Lai X, Brinch L, Ruud E, Drolsum L (2018) Ocular findings and ocular graft-versus-host disease after allogeneic stem cell transplantation without total body irradiation. Bone Marrow Transplant

16. Diep PP, Melberg HO, Brinch L, Buechner J, Floisand Y, GeddeDahl T et al (2018) Cost-utility of allogeneic hematopoietic stem cell transplantation in Norway. Bone Marrow Transplant 53(5): 657-660

17. World Health Organization (2018) Obesity and overweight [Web page] [Available from: www.who.int/topics/obesity/en/

18. World Health Organization (2011) Global Strategy on Diet, Physical Activity and Health [Web page]. [Available from: http:// www.who.int/dietphysicalactivity/factsheet_adults/en/

19. Jagasia MH, Greinix HT, Arora M, Williams KM, Wolff D, Cowen EW, Palmer J, Weisdorf D, Treister NS, Cheng GS, Kerr H, Stratton P, Duarte RF, McDonald GB, Inamoto Y, Vigorito A, Arai S, Datiles MB, Jacobsohn D, Heller T, Kitko CL, Mitchell SA, Martin PJ, Shulman H, Wu RS, Cutler CS, Vogelsang GB, Lee SJ, Pavletic SZ, Flowers MED (2015) National Institutes of Health consensus development project on criteria for clinical trials in chronic graft-versus-host disease: I. the 2014 diagnosis and staging working group report. Biol Blood Marrow Transplant 21(3): $389-401$ e1

20. Macintyre N, Crapo RO, Viegi G, Johnson DC, van der Grinten CP, Brusasco V, Burgos F, Casaburi R, Coates A, Enright P, Gustafsson P, Hankinson J, Jensen R, McKay R, Miller MR, Navajas D, Pedersen OF, Pellegrino R, Wanger J (2005) Standardisation of the single-breath determination of carbon monoxide uptake in the lung. Eur Respir J 26(4):720-735

21. Wanger J, Clausen JL, Coates A, Pedersen OF, Brusasco V, Burgos $F$ et al (2005) Standardisation of the measurement of lung volumes. Eur Respir J 26(3):511-522

22. Quanjer PH, Stanojevic S, Cole TJ, Baur X, Hall GL, Culver BH, Enright PL, Hankinson JL, Ip MSM, Zheng J, Stocks J, the ERS Global Lung Function Initiative (2012) Multi-ethnic reference values for spirometry for the 3-95-yr age range: the global lung function 2012 equations. Eur Respir J 40(6):1324-1343

23. Quanjer PH, Tammeling GJ, Cotes JE, Pedersen OF, Peslin R, Yernault JC (1993) Lung volumes and forced ventilatory flows. Report Working Party Standardization of Lung Function Tests, European Community for Steel and Coal. Official Statement of the European Respiratory Society. Eur Respir J Suppl 16:5-40

24. Pellegrino R, Viegi G, Brusasco V, Crapo RO, Burgos F, Casaburi $\mathrm{R}$, Coates A, van der Grinten C, Gustafsson P, Hankinson J, Jensen R, Johnson DC, MacIntyre N, McKay R, Miller MR, Navajas D, Pedersen OF, Wanger J (2005) Interpretative strategies for lung function tests. Eur Respir J 26(5):948-968

25. Lang RM, Badano LP, Mor-Avi V, Afilalo J, Armstrong A, Ernande L, Flachskampf FA, Foster E, Goldstein SA, Kuznetsova T, Lancellotti P, Muraru D, Picard MH, Rietzschel ER, Rudski L, Spencer KT, Tsang W, Voigt JU (2015) Recommendations for 
cardiac chamber quantification by echocardiography in adults: an update from the American Society of Echocardiography and the European Association of Cardiovascular Imaging. Eur Heart J Cardiovasc Imaging 16(3):233-270

26. Balke B, Ware RW (1959) An experimental study of physical fitness of Air Force personnel. U S Armed Forces Med J 10(6):675688

27. Edvardsen E, Hansen BH, Holme IM, Dyrstad SM, Anderssen SA (2013) Reference values for cardiorespiratory response and fitness on the treadmill in a 20-to 85-year-old population. Chest. 144(1): 241-248

28. Borg GA (1982) Psychophysical bases of perceived exertion. Med Sci Sports Exerc 14(5):377-381

29. American Thoracic Society, American College of Chest Physicians (2003) ATS/ACCP statement on cardiopulmonary exercise testing. Am J Respir Crit Care Med 167(2):211-277

30. Wasserman K, Hansen JE, Sue DY, Stringer WW, Whipp BJ (2005) Principles of exercise testing and interpretation. Fourth ed: Lippincott Williams and Wilkins: 133-196

31. Poggio R, Arazi HC, Giorgi M, Miriuka SG (2010) Prediction of severe cardiovascular events by VE/VCO2 slope versus peak VO2 in systolic heart failure: a meta-analysis of the published literature. Am Heart J 160(6):1004-1014

32. Wood WA, Deal AM, Reeve BB, Abernethy AP, Basch E, Mitchell SA, Shatten C, Hie Kim Y, Whitley J, Serody JS, Shea T, Battaglini C (2013) Cardiopulmonary fitness in patients undergoing hematopoietic SCT: a pilot study. Bone Marrow Transplant 48(10):13421349

33. Abugideiri M, Nanda RH, Butker C, Zhang C, Kim S, Chiang KY, Butker E, Khan MK, Haight AE, Chen Z, Esiashvili N (2016) Factors influencing pulmonary toxicity in children undergoing allogeneic hematopoietic stem cell transplantation in the setting of total body irradiation-based myeloablative conditioning. Int $\mathrm{J}$ Radiat Oncol Biol Phys 94(2):349-359

34. Smith WA, Li C, Nottage KA, Mulrooney DA, Armstrong GT, Lanctot JQ et al (2014) Lifestyle and metabolic syndrome in adult survivors of childhood cancer: a report from the St. Jude Lifetime Cohort Study. Cancer 120(17):2742-2750

35. Stensvold D, Nauman J, Nilsen TI, Wisloff U, Slordahl SA, Vatten L (2011) Even low level of physical activity is associated with reduced mortality among people with metabolic syndrome, a population based study (the HUNT 2 study, Norway). BMC Med 9:109

36. Holmqvist AS, Chen Y, Wu J, Battles K, Bhatia R, Francisco L, Hageman L, Kung M, Ness E, Parman M, Salzman D, Wadhwa A, Winther JF, Rosenthal J, Forman SJ, Weisdorf DJ, Armenian SH, Arora M, Bhatia S (2018) Assessment of late mortality risk after allogeneic blood or marrow transplantation performed in childhood. JAMA Oncol 4(12):e182453

37. Armenian SH, Sun CL, Francisco L, Steinberger J, Kurian S, Wong FL, Sharp J, Sposto R, Forman SJ, Bhatia S (2008) Late congestive heart failure after hematopoietic cell transplantation. J Clin Oncol 26(34):5537-5543

38. Rotz SJ, Dandoy CE, Taylor MD, Jodele S, Jefferies JL, Lane A, elBietar JA, Powell AW, Davies SM, Ryan TD (2017) Long-term systolic function in children and young adults after hematopoietic stem cell transplant. Bone Marrow Transplant 52(10):1443-1447

39. Vandekerckhove K, De Waele K, Minne A, Coomans I, De Groote K, Panzer J et al (2019) Evaluation of cardiopulmonary exercise testing, heart function, and quality of life in children after allogenic hematopoietic stem cell transplantation. Pediatr Blood Cancer 66(1):e27499

40. Lie HC, Rueegg CS, Fossa SD, Loge JH, Ruud E, Kiserud CE (2019) Limited evidence of non-response bias despite modest response rate in a nationwide survey of long-term cancer survivorsresults from the NOR-CAYACS study. J Cancer Surviv 13(3):353363

Publisher's note Springer Nature remains neutral with regard to jurisdictional claims in published maps and institutional affiliations. 